\title{
AVALIAÇÃO: UMA ETAPA FUNDAMENTAL NO PROCESSO DE ESCRITA
}

\author{
EVALUATION: A FUNDAMENTAL STEP IN THE WRITTEN PROCESS
}

\author{
Michele Batista da Silva ${ }^{1}$, Taíse Simioni ${ }^{2}$ \\ ${ }^{1}$ Fundação Bradesco (FB), Bagé, RS, Brasil \\ michibatista.2011@gmail.com \\ ${ }^{2}$ Universidade Federal do Pampa (UNIPAMPA), Bagé, RS, Brasil \\ taisesimioni@unipampa.edu.br
}

Recebido em 27 jul. 2018

Aceito em 14 ago. 2018

Resumo: O presente trabalho visa apresentar um recorte de uma pesquisa realizada por da Silva (2016) em sua dissertação de mestrado e tem por foco a avaliação do processo de escrita, mais precisamente da escrita de notícias no Ensino Fundamental. O público da pesquisa realizada foi composto por alunos do $8^{\circ}$ ano de uma escola da Rede Municipal de Bagé (RS). Na perspectiva adotada neste trabalho, avaliação diferencia-se de mera mensuração, pois pode ocorrer de diversas formas, com objetivos e finalidades específicos. Assim, explicitamos o passo a passo das estratégias de avaliação desenvolvidas juntamente com o corpo discente, como é o caso da avaliação horizontal, estratégia apresentada por Antunes (2006). Durante a intervenção pedagógica aqui analisada, tanto a professora-pesquisadora quanto os alunos avaliaram todas as etapas de produção da notícia, desde o título e lead até a escrita do corpo textual, segundo critérios pré-estabelecidos. Concluímos que é de suma importância que o escritor/autor compreenda que um texto não é escrito em apenas uma tentativa e que é necessário haver um distanciamento temporal entre uma versão e outra de cada etapa de produção do texto, para que haja evolução na escrita de forma global, o que inclui a avaliação processual de aspectos de análise linguística (como a observação de elementos coesivos e morfossintáticos, por exemplo), assim como de aspectos estruturais e composicionais.

Palavras-chave: Avaliação. Produção escrita. Devolutiva.

\begin{abstract}
The present paper intends to present a snippet of a research accomplished by da Silva (2016) in her Master degree dissertation, and it is focused on evaluation of the written process, more precisely of the written of news in the elementary school. The target audience of the research was composed by 8th year students from a school of the municipal school network of Bagé (RS). In the perspective adopted in this work, the evaluation differs from mere measurement, because it can occur in several ways, with specific objectives and goals. Thus, we show the step by step of the strategies of evaluation developed with the students, as in the case of horizontal evaluation, a strategy presented by Antunes (2006). During the pedagogical intervention presented in this article, both the researcher teacher and the students evaluated all steps of production of the news, since the title and lead, until the written of the textual body, according to pre-established criteria. We concluded that it is essential that the writer/author understands that a text is not written in only one attempt and that it is necessary to keep a temporal distance between a version and the another one of each step of the text production, in order to have evolution in written in its global form, including the processual evaluation of aspects of linguistic analisys (as the observation of cohesive and morphosyntactic elements, for instance), as well as of structural and compositional aspects.
\end{abstract}

Keywords: Evaluation. Written production. Devolutive. 


\section{Introdução}

Landsmann (1998) diz que a escrita é um meio de expressão que envolve um longo e complexo processo, o qual inspira, com relação ao ambiente escolar, intervenção direta e sistematizada. Neste trabalho, apresentamos um recorte de da Silva (2016). Trata-se da dissertação da primeira autora deste artigo, que tinha por objetivo analisar o processo de escrita, revisão e reescrita do gênero "notícia" no contexto escolar. No recorte que apresentamos aqui, temos como objeto de análise as estratégias de avaliação da escrita.

Avaliação não necessariamente está atrelada a mensuração, pois a primeira independe da segunda. Vianna (2005) explica que avaliação e mensuração são confundidas nas escolas, levando, muitas vezes, à aplicação de provas e testes, que têm sempre como produto final resultados numéricos. Segundo o autor, esses resultados não indicam a real aprendizagem do aluno e podem levar ao que ele denomina como desinformação educacional. Assim, como nossa preocupação não é a mensuração, ao referirmo-nos a avaliação neste trabalho, estamos considerando todo o processo de produção textual, o qual deve ser constantemente avaliado, ora pelo olhar do aluno/autor, ora pelo olhar do professor, ora pelo olhar de um colega ou outro interlocutor. Este tipo de avaliação tem como finalidade que o aluno revise e reorganize o texto escrito, constatando o que está adequado, o que já evoluiu se comparado às escritas anteriores e o que ainda deve evoluir.

Este artigo está organizado da maneira descrita na sequência. Após esta introdução, na segunda seção, apresentamos a fundamentação teórica do trabalho, na qual discutimos o processo de escrita no ambiente escolar e incluímos a avaliação como parte essencial deste processo. A terceira seção se dedica a descrever a metodologia da pesquisa. Discutimos, na quarta seção, os resultados obtidos. Por fim, a quinta seção se destina às considerações finais.

\section{Fundamentação teórica}

Nesta seção, discutimos o processo de escrita no contexto escolar e, enquanto parte indissociável deste processo, refletimos sobre a avaliação. 


\subsection{O processo de escrita no contexto escolar}

A escrita é uma habilidade discursiva estritamente comunicativa e, portanto, varia de acordo com o tempo e com questões culturais, geográficas e sociológicas, dependendo assim da necessidade momentânea de comunicação e de suas convenções. Landsmann (1998), ao explanar sobre a escrita, afirma que cada indivíduo começa onde começam suas recordações e as de um grupo social iniciam quando este grupo pode deixar rastros gráficos das suas experiências, de seus atos comunicativos, de suas intenções ou desejos.

A escrita por si só não é algo isolado e sim um conjunto de habilidades que são desenvolvidas ao longo da vida escolar de um aluno. Quando tratamos sobre a escrita e a leitura, remetendo-as ao ambiente escolar, temos o que Antunes (2006) e Rocha (1999) chamam de textualização.

Antunes (2006) percebe o estudo dos gêneros em ambiente escolar como "textualização" porque os gêneros saem de suas esferas sociais reais e são adaptados à sala de aula em uma vivência fictícia. A crítica da autora é em relação ao foco que é dado em sala de aula, que, na maioria das vezes, prima pela estrutura composicional, ou o texto, simplesmente, acaba servindo de pretexto para análise gramatical. Rocha (1999), por sua vez, chama a atenção à complexidade inerente a este processo, que envolve o(s) significado(s) de acordo com cada situação discursiva, o assunto, os possíveis interlocutores do discurso, assim como as condições de produção da escrita.

Barbarini (2011) denomina a "textualização" como "didatização dos gêneros". A autora apresenta a preocupação dos documentos oficiais em contextualizar o estudo da Língua Portuguesa aproximando-o à realidade discursiva, reconhecendo que nos gêneros do discurso são levados em consideração: situações sociocomunicativas em que estão inseridos, intenções do discurso, aspectos linguísticos que possibilitam a comunicação entre locutor e interlocutores, contudo sem deixar de seguir uma "estrutura relativamente estável", como compreende Bakhtin (2011). Porém, o questionamento presente em seu texto é quanto à aplicabilidade deste caminho ora "ditado", já que muitos docentes não têm conhecimento aprofundado da teoria dos gêneros do discurso, podendo equivocar-se quanto a sua prática, sem 
perceber que o foco, nesse estudo, é o desenvolvimento da competência discursiva dos alunos e não uma padronização.

Nas escolas brasileiras, uma queixa diária dos professores é que, ao proporem momentos de produção textual escrita, muitos alunos pouco escrevem e alguns, ainda, nada escrevem. Pode-se refletir com isso sobre as estratégias de escrita, se são ou não levadas a contextos reais, com o intuito de fazerem com que os discentes as percebam como tais. Condemarín e Medina (2005) afirmam que a escrita é um ato fundamentalmente comunicativo e, sendo assim, se torna importante que haja uma situação real, um destinatário real e propósitos reais. As autoras ainda reiteram que o texto constitui o resultado de um trabalho de escrita, de leitura crítica e de reescrita.

Condemarín e Medina (2005) citam um conjunto de operações intelectuais complexas que deverão ser dominadas pelos partícipes das tarefas de ensino e aprendizagem, no caso, professor e aluno: pensar o escrito em seu conjunto; estruturá-lo em texto, parágrafos ou capítulos; assegurar a coerência entre esses componentes; reler o texto criticamente; antecipar as reações do leitor para avaliar a pertinência das opções do enunciado; reescrever o texto.

Antunes (2006) diz que, no que se refere às atividades em torno da escrita, ainda se pode constatar: um processo que não valoriza a interferência decisiva do aprendiz; práticas mecânicas e periféricas, centradas, inicialmente, em habilidades motoras e, em seguida, na memorização de regularidades ortográficas, sendo que ainda persiste a ideia de que não saber escrever é escrever com equívocos ortográficos; a prática de uma escrita artificial e sem expressão com atividades de listagem de palavras isoladas, descontextualizadas; práticas sem função, sem valor interacional, assim como sem autoria e recepção; a escrita como exercitação de aspectos irrelevantes da língua como: separação silábica, reconhecimento de dígrafos, encontros vocálicos, etc.; ou seja, práticas sem planejamento prévio, improvisadas. Segundo a autora, a escrita já faz parte do ser, do sujeito aprendiz quando quer se comunicar livremente, mas pode ser desestimulada por práticas mal planejadas.

\subsection{A avaliação no processo de escrita}


A avaliação, em alguns ambientes, é equivocadamente confundida com mensuração, como foi mencionado anteriormente. Avaliar independe de atribuir nota, de medir quantitativamente uma realidade que depende de situações diversas como: contexto de produção, o ser avaliado, o próprio avaliador, conhecimento prévio e intencionalidade de ambas as partes.

Revisão e reescrita são partes importantes do processo de escrita. Sem essas etapas, é provável que os estudantes não compreendam as minúcias e peculiaridades do dito processo e avaliem sua tentativa, talvez uma única versão, comparada à escrita de profissionais e/ou à dos próprios colegas, como inferior e sem prestígio. E o que seria revisar, se não avaliar? Ao revisar, o locutor/autor debruça-se sobre o objeto de estudo com olhar desconfiado, desafiando assim suas próprias palavras. Ou tem ainda a oportunidade de disponibilizar sua "criação" a outros interlocutores para que também possam perceber possibilidades de melhoria neste objeto.

O texto é o resultado de um trabalho de escrita, de leitura analítica, crítica e de reescrita. Passarelli (2004) apresenta habilidades desenvolvidas com o trabalho de exercícios de energia criativa em sala de aula, as quais são: avivar ideias e planejar; esboçar ou testar suas ideias; discutir com outros; revisar e aperfeiçoar; dividir ou tornar público (socializar) o que foi criado. Todas essas pequenas partes ou etapas devem ser constantemente avaliadas, seja pelo professor, pelo próprio autor ou pelos colegas.

Os Parâmetros Curriculares Nacionais, ao explanarem sobre o processo de produção textual, dizem que a "refacção" (BRASIL, 1998, p. 77) é um elemento do processo de escrita. Um texto só está pronto para ser socializado depois de serem realizadas reformulações e sucessivas versões. Um planejamento com momentos distintos de produção e reescrita produz efeitos positivos:

- permite que o aluno se distancie de seu próprio texto, de maneira a poder atuar sobre ele criticamente;

- possibilita que o professor possa elaborar atividades e exercícios que forneçam os instrumentos linguísticos para o aluno poder revisar o texto.

Nesta perspectiva, a refacção que se opera não é mera higienização, mas profunda reestruturação do texto, já que entre a primeira versão e a definitiva uma série de atividades foi realizada (BRASIL, 1998, p. 77). 
Essa passagem dos Parâmetros Curriculares Nacionais sugere que o trabalho com textos seja realizado por partes, o que, para muitos docentes, ainda parece não ser possível, já que as propostas de produção escrita geralmente caem em um recorrente equívoco: tornar o processo de escrita um único momento avaliativo. De acordo com Passarelli (2004), raramente as crianças releem ou expõem as partes de seu escrito, devido à mediação do professor, que não integra essa prática ao cotidiano escolar e/ou exige que o aluno realize todas as etapas do texto de uma só vez e ainda o avalia. Se houver, no entanto, momentos diversos para a produção das partes do texto, o discente conseguirá visualizar sua produção com olhar crítico, já que seu olhar não estará preso ao todo e/ou cansado do processo, a cada retomada.

Landsmann (1998) analisou duas práticas diferentes na produção de texto. À primeira denominou dizer o conhecimento, costumeira em escritores novatos, e à segunda, transformar o conhecimento, comum a especialistas. A primeira prática resume-se a citar aspectos relevantes à produção textual, enquanto a segunda refere-se à construção do texto de forma comprometida e qualitativa, sendo trabalhadas as etapas de produção em momentos distintos: geração de ideias, elaboração do pré-texto e rascunhos e revisão. Em seguida a autora utiliza-se da expressão "transformação do conhecimento" (LANDSMANN, 1998, p. 97), sugerindo uma transformação escolar pois a escola tem a escolha de desenvolver escritores especialistas ou deixá-los no patamar de novatos, enquanto não se modificarem internamente com o intuito de compreender a escrita como um processo. A escola, para a autora, tem o papel fundamental como intervenção educativa e sistemática.

Ainda tratando de revisão do texto, já citamos as correções ortográficas como foco como algo equivocado, o que não quer dizer que não deva ocorrer uma análise linguística do que foi escrito. A análise linguística, por sua vez, ultrapassa as regularidades ortográficas e analisa a fundo os elementos linguísticos constituintes de um texto. Mendonça (2006) denomina análise linguística $(A L)$ a reflexão sobre o sistema linguístico e sobre os usos da língua. A AL é vista, deste modo, como um dos variados eventos de letramento escolar. A análise em questão não tem como objetivo eliminar as gramáticas da sala de aula, pois a reflexão da língua também se dá por meio da gramática e inclusive por meio de nomenclaturas, como afirma a 
autora, porém com uma perspectiva sociointeracionista, ou seja, partindo do todo discursivo e não de pequenas partes, como frases, orações e períodos. Neste paradigma, a $A L$ é realizada em consonância com as condições de produção do discurso: interlocutores, propósitos e/ou intencionalidades, gêneros, suporte, etc., objetivando a reflexão sobre os elementos e fenômenos linguísticos, assim como estratégias linguísticas, com foco na materialidade linguística. Ainda Mendonça (2006) explica que elementos como morfologia, vocabulário, sintaxe, modalização, rimas, aliteração, coesão e estratégias argumentativas podem estar envolvidos na prática de $\mathrm{AL}$, alguns até simultaneamente, contudo, visando especular a produção de sentidos e/ou como formar leitores e escritores eficientes e autônomos, já que é estimulada a compreensão dos usos e do sistema linguístico.

Segundo Geraldi (2006a), uma boa prática na análise linguística seria partir de textos que apresentam equívocos e, portanto, são ricos como objeto de estudo. $A$ partir da análise de questões em que o próprio aluno encontrou dificuldades, as respostas, ou seja, as estratégias de possíveis resoluções dos problemas encontrados surgirão de seu próprio texto. Esses problemas deverão ser trabalhados individualmente, com momentos específicos, pois de nada adianta querer resolver todos os problemas em uma produção textual de uma só vez. Essa prática apenas confundiria os discentes, sem desenvolver suas percepções linguísticas.

Para que a revisão da escrita como um processo tenha êxito, se faz necessário que haja devolutivas claras. O primeiro passo que o educador deve ter em mente é que as devolutivas são uma ferramenta fundamental nesse processo. O professor, ao passo que acompanha o processo de escrita de seus alunos, com um planejamento voltado às partes deste, sabe o foco de cada momento e, portanto, o que deve ser analisado em cada etapa. Se o texto for tratado como um todo e avaliado ao final da produção, o professor não terá critérios suficientes que abranjam todos os aspectos da escrita, ou, ao menos, os mais importantes para a idade-série do aluno ou para as expectativas do momento.

O antigo método de recolher redações ao final do bimestre de todas as turmas, sentar em casa, em silêncio, para as "correções", não é um caminho adequado. Ao insistir nesse método, caímos no erro de padronizar as expectativas em relação a 
escritas diferentes de pessoas diversas com níveis de escrita, assim como idade e série, distintos. Ao tratar a escrita como um processo, iniciando-se pelo planejamento, a estimativa é que o equívoco acima ilustrado não se repita.

Para Camargo (1997), as devolutivas consistem em planejar, sistematizar, utilizando-se de momentos plurais. Esse planejamento deverá dizer respeito a todo um processo de construção conjunta de conhecimento, sendo passível de questionamentos e intervenções de ambos os participantes do processo (professor e aluno). Desta forma, o educador deposita créditos no pensar e no agir do aluno, privilegiando-o não com respostas prontas, e sim com a oportunidade de refazer após hipotetizar sobre erros e acertos. Deste modo, o educando se torna partícipe do processo de ensino/aprendizagem, já que também avalia suas práticas.

Muito se fala em interlocutor real no processo de escrita. Entretanto, nas escolas, muitas vezes, o único leitor dos textos de um aluno é o professor, que, por vezes, não exerce a função de um interlocutor real porque não interage com o texto para além de realizar uma avaliação com fins de mensuração. O aluno escreve pensando no que o professor deseja, em quais são suas expectativas e na avaliação que surgirá do produto que entregar. Essa situação gera desconforto e obrigatoriedade relacionada à escrita.

Mas será que todo produto gerado em sala de aula deverá ser mensurado? Avaliar, diferentemente de mensurar, é acompanhar, analisar se os objetivos propostos estão a caminho de ser contemplados e se as capacidades dos alunos estão ou não sendo desenvolvidas. Condemarín e Medina (2005) comentam que, para que o processo avaliativo retroalimente o processo de produção de textos, é necessário primeiramente entender a natureza do ato de escrever; situar a atividade de escrita em projetos que Ihe atribuam sentido; formular critérios que orientem os alunos sobre os saberes que devem construir e levem o professor a uma melhor condução da aprendizagem de seus educandos. Para que isso aconteça, fazem-se necessárias estratégias como revisão e reescrita. Os procedimentos de escrita, revisão e reescrita devem ser previamente planejados, com objetivos claros a cada etapa, com o intuito de que os envolvidos percebam o processo como uma construção. 
Hoffmann (1993) apresenta, como método avaliativo, a avaliação mediadora, em que o professor não é o foco do processo, mas faz parte deste, como um meio entre o aprendiz, suas habilidades já desenvolvidas, suas percepções, o objeto de estudo, o meio social e o desenvolvimento de novos saberes. Outro aspecto relevante para a autora é a capacidade de autoavaliação, que pode ser estruturada a partir de trabalhos em grupos como um gatilho para a reflexão de cada aluno. Alguns docentes são resistentes à proposta de realizar atividades em grupos ou de que um colega avalie o outro ou que o próprio aluno se avalie. Essa resistência perdurará enquanto o educador se mantiver no papel de "domínio do saber", sem perceber que a avaliação não visa apenas mensuração, mas a consolidação do aprendizado. A autoavaliação para Hoffmann (2002) só tem significado enquanto reflexão do educando, tomada de consciência individual sobre suas aprendizagens e condutas cotidianas, de forma natural e espontânea, como aspecto intrínseco ao seu desenvolvimento e com o objetivo de ampliar o âmbito de suas possibilidades iniciais, favorecendo, assim, sua superação em termos intelectuais.

O acompanhamento do professor em relação às tarefas realizadas pelo educando em todos os graus do ensino deve culminar com uma devolutiva, como foi mencionado anteriormente. Nesta devolutiva, o professor se coloca como interlocutor do texto do aluno, intervindo no que for necessário para a melhoria de sua produção, como sugere Geraldi (2006b), visando um futuro interlocutor real, conforme a esfera de atividade humana em que é inserido o gênero produzido.

\section{Metodologia de intervenção pedagógica}

Este trabalho adotou o tipo de pesquisa "lewiniano" denominado pesquisaação, a qual acontece em forma triangular e contínua (ação - investigação formação), conforme Latorre (2003).

O público selecionado para o desenvolvimento da pesquisa foi uma turma de $8^{\circ}$ ano de uma escola da Rede Pública Municipal de Bagé (RS). Essa escola está situada em uma área central da cidade, a qual recebe discentes tanto das proximidades do local, como também de bairros mais afastados e até da zona rural. 
A turma em questão era composta por 34 alunos, entre 13 e 15 anos, sendo que havia 18 meninas e 16 meninos. ${ }^{1}$

Para este artigo, foram analisadas as etapas do processo de escrita de apenas um aluno, como exemplo da evolução neste processo proporcionada por momentos diversos de avaliação, retomada e reorganização textual. O aluno em questão foi escolhido por tratar-se de um educando que participou de todas as etapas do processo, já que esteve presente em todas as aulas, e apresentou evolução constante no decorrer do processo de escrita, revisão/avaliação e reescrita do gênero trabalhado.

O gênero "notícia" foi escolhido para a proposta em análise por se tratar de um gênero naturalmente maleável, o qual varia de acordo com o público-alvo, assim como conforme o veículo que processa a informação e/ou as intenções do autor, sendo assim um gênero rico em possibilidades de escrita.

Como parte da pesquisa de Mestrado desenvolvida pela primeira autora deste artigo, foi proposta uma sequência com a realização de 12 atividades voltadas aos elementos constitutivos da escrita, desde o diagnóstico dos conhecimentos prévios sobre o gênero "notícia", até a socialização e a divulgação das produções dos alunos, que ocorreu em forma de entrega de um impresso informativo aos demais colegas do Ensino Fundamental. A professora titular da turma foi convidada a participar do projeto aqui descrito como colaboradora, ou seja, participando das etapas do processo e também mediando-o.

O desenvolvimento das atividades ocorreu entre os meses de maio e junho de 2016. O direcionamento dado para que a reescrita fosse inserida no cotidiano da escola onde o projeto foi aplicado foi o respeito aos objetivos relacionados a cada momento da escrita, objetivos esses claros aos educandos, para que eles compreendessem as expectativas da professora-pesquisadora e pudessem obter êxito a cada etapa desenvolvida.

Para o presente trabalho, o foco a ser analisado são as formas variadas de retomadas e devolutivas exploradas, visando à mediação em cada etapa do trabalho, assim como a autoavaliação por parte dos educandos.

\footnotetext{
${ }^{1}$ Os responsáveis pelos alunos assinaram uma autorização segundo a qual permitiam a coleta dos dados durante a intervenção e sua posterior divulgação.
} 
Os resultados aqui presentes foram analisados qualitativamente. Os registros feitos ao longo da aplicação da proposta contemplam, além de questionários e produções textuais, também um vídeo que era gravado pela primeira autora deste artigo ao término de cada atividade e um diário reflexivo escrito.

\section{Análise dos resultados: avaliar para perceber o caminho trilhado e visualizar o ponto de chegada}

A fim de que se possa ter uma compreensão global da proposta que está sendo analisada neste trabalho, serão apresentadas, brevemente, as atividades que a constituíram. Uma atenção mais detalhada será dada às produções de um único aluno (MI), mostrando seu processo de escrita, avaliação, revisão e reescrita, o que permite um acompanhamento de sua evolução no decorrer do processo.

Como foi mencionado anteriormente, a proposta que apresentamos foi composta por 12 atividades. A sequência das atividades é mostrada a seguir.

$A$ atividade 1 foi constituída por uma sondagem. Neste momento, foi entregue aos discentes um questionário com questões voltadas ao gênero "notícia". Este questionário foi avaliado como diagnóstico da turma. Os questionários foram devolvidos à professora-pesquisadora e discutidos com a turma na aula seguinte. Ainda dentro desta primeira atividade, foi proposta aos alunos uma produção textual. Para tal, os alunos puderam visualizar três imagens e deveriam escolher uma para a produção de uma notícia.

No Quadro 1, apresentamos a transcrição da produção inicial de Ml, que optou por noticiar os acontecimentos de duas imagens.

Quadro 1 - Produção inicial
Transcrição:
$1^{\underline{a}-}$ - Um protesto começou na grande São Paulo nesta Quinta-Feira 6/5/2009, o protesto foi ide- alizado pelos trabalhadores dos correios que estão esperando o aumento dos salários, os trabalhadores fizeram cartazes, placas, mensagens e fizeram uma barricada com pneus no meio da rua, não sabemos até quando o protesto vai durar.
2a- Um ponto de acúmulo de água nas ruas de bagé duranta as chuvas dessas últimas semanas é 
um perigo para a população. Recentemente muitos veículos deslizam nessa Rua, mas uma verdadeira tragédia aconteceu ontem a tarde, um veículo com turistas vindos do Uruguay derrapou e bateu em uma árvore, felizmente os passageiros saíram com apenas ferimentos leves e ninguém morreu.

Esta era a primeira vez que, no ano em questão, o aluno Ml produzia uma notícia em aula. O foco da avaliação, neste momento, era o que o aluno já sabia, ou seja, seus conhecimentos prévios sobre o gênero proposto, para que, a partir disso, a professora-pesquisadora pudesse traçar estratégias que propiciassem a evolução em sua escrita, assim como na escrita dos demais discentes.

É perceptível que o aluno refletiu sobre como noticiar um fato, sendo cuidadoso ao apresentar: o fato (o quê); o tempo em que ocorreu o fato (quando); as pessoas relacionadas (quem); o porquê do protesto (por que), no caso da primeira notícia; e como ocorreu o fato (como). Por outro lado, há um problema de coerência no segundo texto, no momento em que o aluno se refere a uma "grande tragédia" que, de fato, não tem correspondência nos fatos narrados. Além disso, os textos não apresentam título e trazem equívocos referentes aos sinais de pontuação.

Para a realização da atividade 2 , os alunos foram encaminhados ao laboratório de informática da escola. Lá foram apresentadas as etapas do projeto de que eles fariam parte e foi discutida a importância de pensarem na escrita como um processo, assim como na avaliação de cada etapa como uma necessidade. Ocorreu, também, uma conversa com os alunos sobre o gênero "notícia" e sua maleabilidade, características estilísticas que não são regras, mas que são perceptíveis na maioria dos veículos de divulgação deste gênero e que possibilitam o reconhecimento deste frente a outros gêneros.

$\mathrm{Na}$ sequência, os discentes foram dispostos direcionados a uma imagem apresentada no projetor e analisaram as características estruturais, assim como temáticas comuns a uma notícia em veículo impresso, notícia esta veiculada em um jornal local e escrita por um profissional. Tratou-se de um momento imprescindível no processo de escrita, já que se voltou ao estímulo da curiosidade dos educandos sobre o gênero trabalhado, além de lhes ser apresentada a esfera social em que o gênero é inserido e suas características peculiares. 
O passo seguinte foi apresentar, com o auxílio de notícias expostas em datashow, o que seriam título, lead, corpo, depoimento, etc. Para isto, foram apresentados quatro exemplos de textos criados na aula anterior por alunos da turma em questão. Esses textos foram previamente digitados e analisados pela professora-pesquisadora quanto ao objetivo inicial do gênero - noticiar um fato de modo claro, com aparência de objetividade, direto - e também quanto a algumas características comuns a este gênero, com o intuito de ser realizado posterior estudo com o grupo de discentes. As produções dos alunos não foram identificadas, para que os discentes as percebessem e analisassem por suas qualidades e proximidade com o texto jornalístico lido anteriormente e não por motivos pessoais.

A atividade 3 foi um momento voltado à leitura de notícias diversas e à análise das características do gênero "notícia" impresso e online. Inicialmente, foram apresentados dois vídeos, contendo a divulgação de um mesmo fato, porém noticiado em veículos diferentes. ${ }^{2}$ Os alunos perceberam que o primeiro vídeo, embora apresentasse a opinião de um representante da população local, não emitia opiniões do jornal, já o segundo vídeo sim. A maioria dos discentes já conhecia o programa de televisão em que foi veiculado o segundo vídeo, tecendo comentários em que relacionaram o apresentador com outros de programas de jornalismo diversos que também costumam apresentar sua opinião de modo enfático. Neste momento os discentes puderam repensar o que haviam escrito na primeira aula, pois era novidade a ideia de que todo discurso tem seu "lado" e, portanto, não há discurso imparcial. Também era novidade a ideia de que em aula poderiam ser exploradas diversas intenções na linguagem, desde uma escrita com maior aparência de objetividade até uma escrita sensacionalista, dependendo dos recursos estilísticos que fossem utilizados e, principalmente, das intencionalidades do autor.

A proposta teve continuidade com a organização dos discentes em pequenos grupos, divididos por temáticas: análise da estrutura do gênero; noticiabilidade; intenções do autor; veículos ou suportes de veiculação do gênero. Cada grupo tinha a finalidade de estudar uma das temáticas, com materiais diversos previamente selecionados pela professora-pesquisadora e/ou com o auxílio da internet. Foram

2 Os vídeos podem ser visualizados nos seguintes endereços eletrônicos: https://www .youtube.com/watch?v=IXUard6C0ag e https://www.youtube.com/watch?v=jpAY3Qr2EW4. 
fornecidos cartolina, lápis de cor, canetas coloridas, jornais e disponibilizados alguns computadores do laboratório de informática, assim como o datashow ficou à disposição dos grupos para a socialização. O envolvimento dos educandos foi intenso. O momento da socialização superou as expectativas, pois os educandos se preocuparam em utilizar uma linguagem adequada à situação discursiva, prepararam material extraclasse em casa e souberam explicar adequadamente a temática que ficou ao encargo de cada grupo.

A atividade 4 teve como tema o planejamento de pauta em um jornal. Os alunos foram levados a um espaço destinado à elaboração, edição e impressão de um jornal local, onde compreenderam como se dão as escolhas das pautas das notícias diárias, além de conhecerem a esfera real onde é produzido o gênero trabalhado. A visita foi previamente agendada, assim como foi organizado, também previamente, um questionário para orientar os alunos quanto ao foco da visita (pautas diárias).

Voltando à escola, os alunos escolheram os temas que queriam abordar em suas produções. Os temas escolhidos para a produção das notícias foram a reforma nas quadras da escola, a festa julina, a doação de leite para uma casa de idosos, a retirada dos bebedouros da escola e os jogos intersséries. A seleção de tais temas revela que os alunos estão atentos ao que acontece na escola e têm sobre o que dizer. É necessário, portanto, que lhes sejam dados voz e ouvidos.

A atividade 5 foi destinada à escrita do título e do lead de uma notícia. O Quadro 2 apresenta a produção de Ml.

Quadro 2 - Escrita do título e do lead

\section{Transcrição:}

Doação de leite ao Asilo José Auta Gomes

Os alunos da escola Antenor Gonsalves Pereira doarão litros de leite ao asilo José Auta Gomes na cidade de Bagé; a doação acontecerá no dia 6/6/2016.

Após receber a devolutiva de sua primeira versão de uma notícia e de estudar as características estruturais e composicionais do gênero notícia, é perceptível a evolução do aluno, ao perceber a necessidade de dar título a seu texto. 
$\mathrm{Na}$ atividade 6, foram realizadas a revisão/avaliação e a reescrita do título e do lead. A estratégia escolhida para isso é o que Antunes (2006) denomina avaliação horizontal, já que os discentes foram reunidos em grupos de três integrantes, sendo que estes deveriam ler suas produções e os demais colegas deveriam analisá-las a partir de critérios dispostos em uma planilha criada pela professora-pesquisadora, de acordo com características comuns ao gênero, mais especificamente ao lead. Os colegas que analisaram esta etapa da produção do aluno Ml consideraram seu texto, na maior parte, adequado, mas pontuaram como parciais: a análise das partes do lead; a coerência na produção do lead; a relação das partes do texto (título e lead) com a proposta de produção. Eles também consideraram regular a utilização de recursos linguísticos, como a ortografia. Isto pode ser observado no Quadro 3, que traz a planilha utilizada para esta etapa e já preenchida com a avaliação do texto de MI.

Quadro 4 - Avaliação horizontal do título e do lead

\begin{tabular}{|c|c|c|c|}
\hline \multicolumn{4}{|l|}{ r } \\
\hline $\begin{array}{l}\text { Objetivos do } \\
\text { Titulo }\end{array}$ & Contempla & Parcialmente & Não contempla \\
\hline $\begin{array}{ll}\text { Ideia } & \text { de } \\
\text { atualidade } & \\
\text { proporcionada } & \\
\text { pelo verbo } & \end{array}$ & & & \\
\hline Relação do título & & & \\
\hline com 0 que se & & & \\
\hline pretende noticiar & & & \\
\hline $\begin{array}{l}\text { Análise das } \\
\text { partes do lead }\end{array}$ & & & \\
\hline $\begin{array}{l}\text { Coerência gerada } \\
\text { na produção do } \\
\text { lead }\end{array}$ & & & \\
\hline $\begin{array}{l}\text { Relação título e } \\
\text { lead }\end{array}$ & & & \\
\hline $\begin{array}{l}\text { Relação das } \\
\text { partes do texto } \\
\text { com a temática } \\
\text { proposta }\end{array}$ & & & \\
\hline $\begin{array}{l}\text { Análise linguística } \\
\text { Ortografia - com } \\
0 \quad \text { auxilio de } \\
\text { dicionário }\end{array}$ & Adequado & Regular & Inadequado \\
\hline Paragrafação & & & \\
\hline $\begin{array}{l}\text { Escolha do léxico } \\
\text { e as relações de } \\
\text { sentido } \\
\text { provocadas por } \\
\text { esta }\end{array}$ & & & \\
\hline
\end{tabular}

É perceptível o rigor utilizado na análise do texto do colega. É importante lembrar que esse rigor simboliza o crivo dos alunos quanto à escrita "do outro", além de também simbolizar as expectativas que eles tinham quanto a esta produção. Uma 
avaliação baseada em critérios é o que defendem Condemarín e Medina (2005) ao afirmarem que deve ser do conhecimento dos alunos os objetivos esperados para a sua produção.

Feita esta avaliação, os alunos reescreveram o título e o lead, como mostra a produção do aluno MI no Quadro 4.

\section{Quadro 4 - Reescrita do título e do lead}

\section{Transcrição:}

Os alunos da escola Antenor Gonçalves Pereira doarão litros de leite ao asilo José Auta Gomes na cidade de Bagé; a doação acontecerá no dia 6/6/2016.

Apesar dos critérios que foram parcialmente atingidos, de acordo a avaliação dos colegas, MI considerou necessário apenas rever a escrita da palavra "Gonçalves", que havia apresentado equívoco ortográfico na versão anterior. Talvez isto possa refletir uma certa falta de confiança na avaliação dos colegas, uma vez que esta prática de avaliação não é recorrente no ambiente escolar.

A atividade 7 se destinou à escrita do corpo textual, como podemos observar no Quadro 5 abaixo.

\section{Quadro 5 - Escrita do corpo textual}

Transcrição:
A arrecadação de leite será até o dia 6/6/2016, o mesmo da entrega.
o objetivo da campanha é alimentar os idosos do asilo José Auta
Gomes, a turma que arrecadar mais leite ganhará uma bola para os
meninos e uma para as meninas. Os alunos que trouxerem mais leite ganha-
rão uma certa notal todos estão colaborando muito.

Sabemos que um escritor profissional não escreve apenas uma versão, pois primeiramente cria esboços, rascunhos. Portanto, houve a necessidade de uma primeira versão do corpo textual, seguida de mais um momento de revisão/avaliação.

Assim, a atividade 8 teve como meta a revisão do corpo textual. Nesta etapa, ocorreu, novamente, a avaliação horizontal (desta vez, em duplas), como revela a segunda planilha, que é apresentada no Quadro 6. Esta planilha foi criada pela 
professora pesquisadora, com foco em elementos essenciais ao corpo textual, e foi preenchida por um colega de Ml.

Quadro 6 - Avaliação horizontal do corpo textual

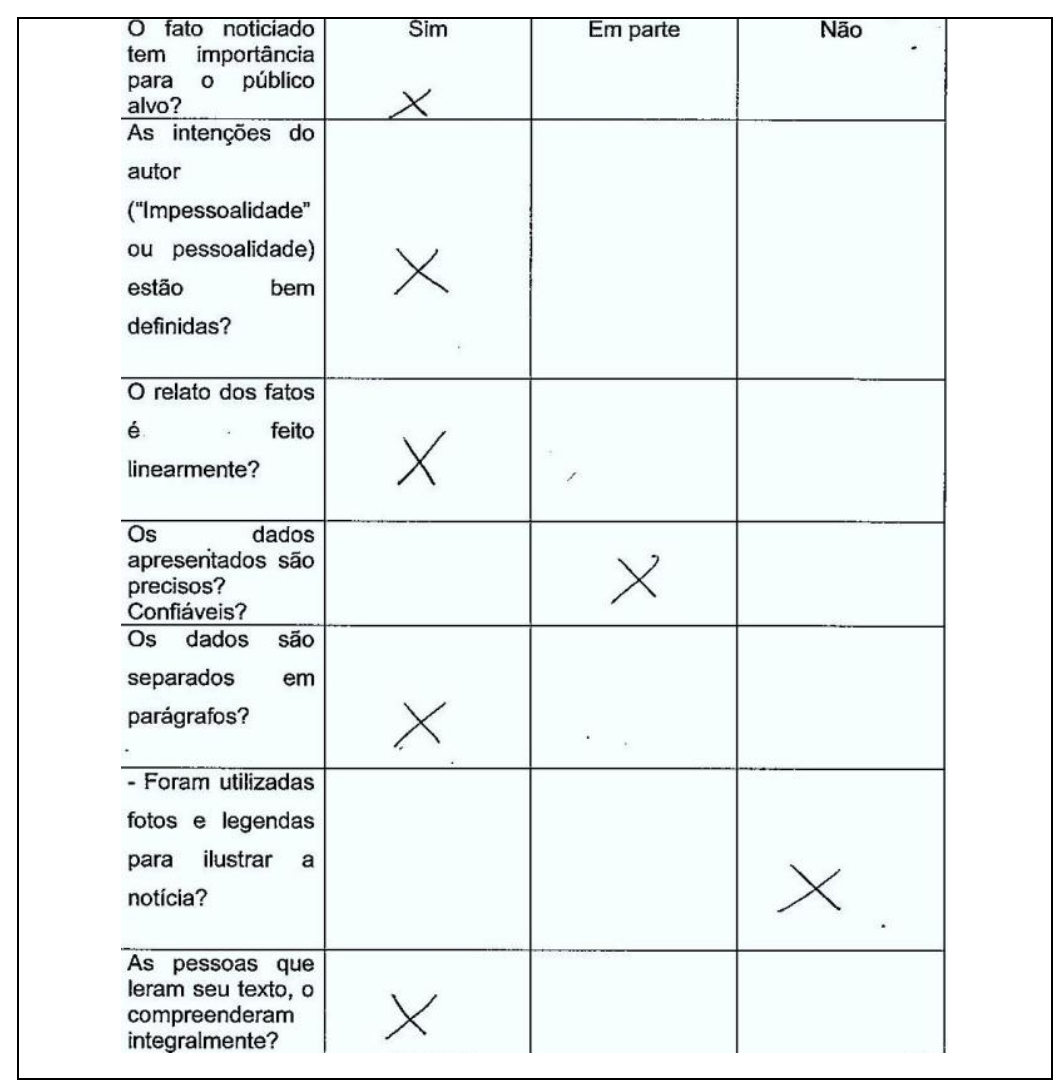

A dupla do aluno MI considerou adequada sua escrita, com exceção dos dados que, para ele, não foram totalmente precisos e confiáveis. Neste momento, fotos ainda não haviam sido incorporadas às notícias.

Durante a atividade 9, ocorreram a reescrita do corpo textual, a digitação da notícia, a busca por imagens para compô-la e a produção de legendas para tais imagens. O Quadro 7 mostra a produção final do aluno MI.

Quadro 7 - Produção final

Doação de leite ao Asilo José e Auta Gomes 


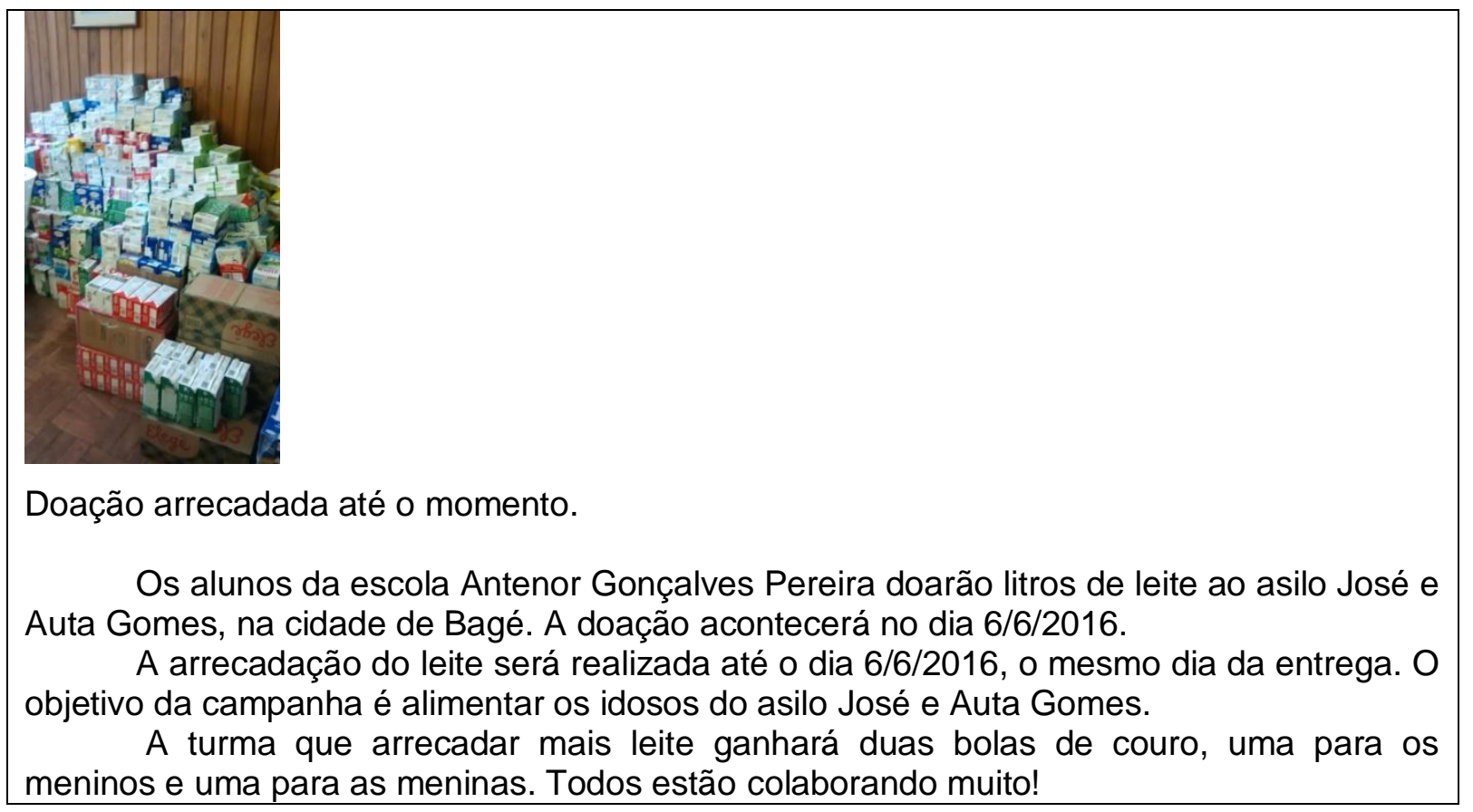

No momento da reescrita e digitação da produção integral, o aluno Ml prestou atenção às questões pontuadas pela professora-pesquisadora, como, por exemplo, a utilização de letra maiúscula e acentuação gráfica. O discente teve necessidade de adequar seu texto após relê-lo mais uma vez, o que traz evidências sobre a importância do distanciamento do texto, que se revela um grande aliado na autoavaliação. Provavelmente, por se tratar de um momento também de digitação, as ferramentas do programa do computador utilizado o tenham auxiliado quanto a aspectos formais do texto. $O$ acréscimo de imagem e legenda colaboraram para instigar a curiosidade de possíveis leitores. Percebe-se que, desta vez, Ml parece ter levado em consideração a avaliação de seu colega, que apontou como parcial a precisão e a confiabilidade dos dados apresentados, uma vez que o trecho que falava sobre a atribuição de uma "certa nota" a quem arrecadasse mais leite foi removida da versão final.

A atividade 10 foi reservada para a continuação das digitações das notícias e o acréscimo de imagem e legenda. $\mathrm{Na}$ atividade 11, ocorreu a organização do impresso informativo. Este foi o penúltimo dia de trabalho com a turma, momento de editoração dos impressos informativos. A partir desta atividade, a turma retornou às aulas com a professora regente, enquanto apenas cinco alunos foram chamados para trabalharem com a professora-pesquisadora na editoração do impresso 
informativo, no laboratório de informática da escola, incluindo o aluno MI. Vários alunos tinham interesse em compor o grupo de editores do impresso informativo, por isso, a escolha do grupo se deu por motivo de participação, habilidades em informática e apropriação do gênero. Após escolher as notícias (apenas cinco, já que se tratava de um primeiro impresso), os "editores" tiveram a oportunidade de rever os tempos verbais, já que algumas produções tratavam de fatos que, ao início do trabalho, ainda não haviam ocorrido e que, ao final, já tinham acontecido. Com essas notícias, foi necessário que os alunos responsáveis (editores) fossem a campo pesquisar maiores detalhes.

$A$ atividade 12 se dedicou à divulgação extraclasse do impresso informativo. A turma indicou dois alunos para a divulgação do impresso informativo nas salas de aula, setores da escola e corredores. Tanto os colegas de outras turmas quanto equipe diretiva, professores e funcionários foram receptivos aos alunos divulgadores.

\section{Considerações finais}

A presente investigação discutiu a importância de uma produção textual ser trabalhada processualmente e, nesse processo, evidenciou-se a necessidade de serem exploradas diferentes estratégias de avaliação de uma produção textual, seja ela a avaliação do próprio autor sobre o seu objeto de estudo ou a avaliação do professor ou de colegas.

Com a diversidade de avaliações de cada etapa do processo de escrita, foi possível que o aluno/escritor percebesse equívocos ou simples esquecimentos ocasionados nas versões anteriores. A cada refacção foram perceptíveis pequenas melhorias que se consolidaram na escrita do educando, já que ele teve, além do trabalho de escrita, também o trabalho de ler as orientações dos "avaliadores", somando-as ao seu crivo pessoal. Com relação à avaliação dos colegas, cabe a observação de que se faz necessário um trabalho constante de avaliação horizontal para que os alunos se sintam confiantes para realizá-la e para que levem, de fato, as observações dos colegas em consideração em suas produções. 
A análise das produções do aluno Ml exemplificou o quanto é perceptível a evolução dos educandos em termos de escrita quando são instigados a avaliar o que eles próprios ou seus pares produziram, por meio de avaliações horizontais, além de possibilitar a análise dessas produções em partes, de acordo com os objetivos do momento (título, lead, corpo textual). Para que os educandos compreendessem a importância do processo de escrita, fez-se necessário que desde o início das atividades de estímulo à escrita os alunos já soubessem qual seria a culminância da proposta pedagógica. Destaca-se, com isso, a relevância do estabelecimento de critérios claramente postos para a avaliação de cada etapa da produção textual.

\section{Referências bibliográficas}

ANTUNES, I. Muito além da gramática: por um ensino de línguas sem pedras no caminho. São Paulo: Parábola Editorial, 2006.

BAKHTIN, M. Estética da criação verbal. São Paulo: Martins Fontes, 2011.

BARBARINI, M. Gêneros, autoria e estilo em textos de $6^{\circ}$ ano do ensino fundamental. São Carlos: UFSCar, 2011.

BRASIL. Secretaria de Educação Fundamental. Parâmetros curriculares nacionais terceiro e quarto ciclos do ensino fundamental: língua portuguesa/ Secretaria de Educação Fundamental. Brasília: MEC/SEF, 1998.

CAMARGO, R. B. de Gestão Democrática e Nova qualidade de Ensino: o conselho de escola e o projeto de interdisciplinaridade. 1997. 370 f. Tese (Doutorado em Educação) - Faculdade de Educação, Universidade de São Paulo, São Paulo, 1997.

CONDEMARÍN, M.; MEDINA, A. Avaliação autêntica: um meio para melhorar as competências em linguagens em comunicação. Porto Alegre: Artmed, 2005.

DA SILVA, M. B. Escrita, revisão e reescrita do gênero "notícia" produzido no ensino fundamental: o passo a passo - construção e implementação de propostas de intervenção. 2016. 154 f. Dissertação (Mestrado em Ensino de Línguas) Universidade Federal do Pampa, Bagé, 2016.

GERALDI, J. W. Unidades básicas do ensino de português. In: GERALDI, J. W. (Org.). O texto na sala de aula: leitura e produção. São Paulo: Ática, 2006a, p. 5979. 
GERALDI, J. W. Escrita, uso da escrita e avaliação. In: GERALDI, J. W. (Org.). 0 texto na sala de aula: leitura e produção. São Paulo: Ática, 2006b, p. 127-131.

HOFFMANN, J. Avaliação mediadora: uma prática em construção da pré-escola à universidade. Porto Alegre: Mediação, 1993.

HOFFMANN, J. Avaliar para promover: as setas do caminho. Porto Alegre: Mediação, 2002.

LANDSMANN, L. Aprendizagem da Linguagem Escrita: processos evolutivos e implicações didáticas. São Paulo: Ática, 1998.

LATORRE, A. La Investigación-Acción. Barcelona: Graó, 2003.

MENDONÇA, M. Análise linguística no ensino médio: um novo olhar, um outro objeto. In: BUNZEN, C.; MENDONÇA, M. (Orgs.) Português no ensino médio e formação do professor. São Paulo: Parábola Editorial, 2006, p.199-226.

PASSARELLI, L. Ensinando a Escrita: o processual e o lúdico. São Paulo: Cortez, 2004.

ROCHA, G. A apropriação das habilidades textuais pela criança. São Paulo: Papirus, 1999.

VIANNA, H. M. Fundamentos de um Programa de Avaliação Educacional. Brasília: Liber Livro Editora, 2005.

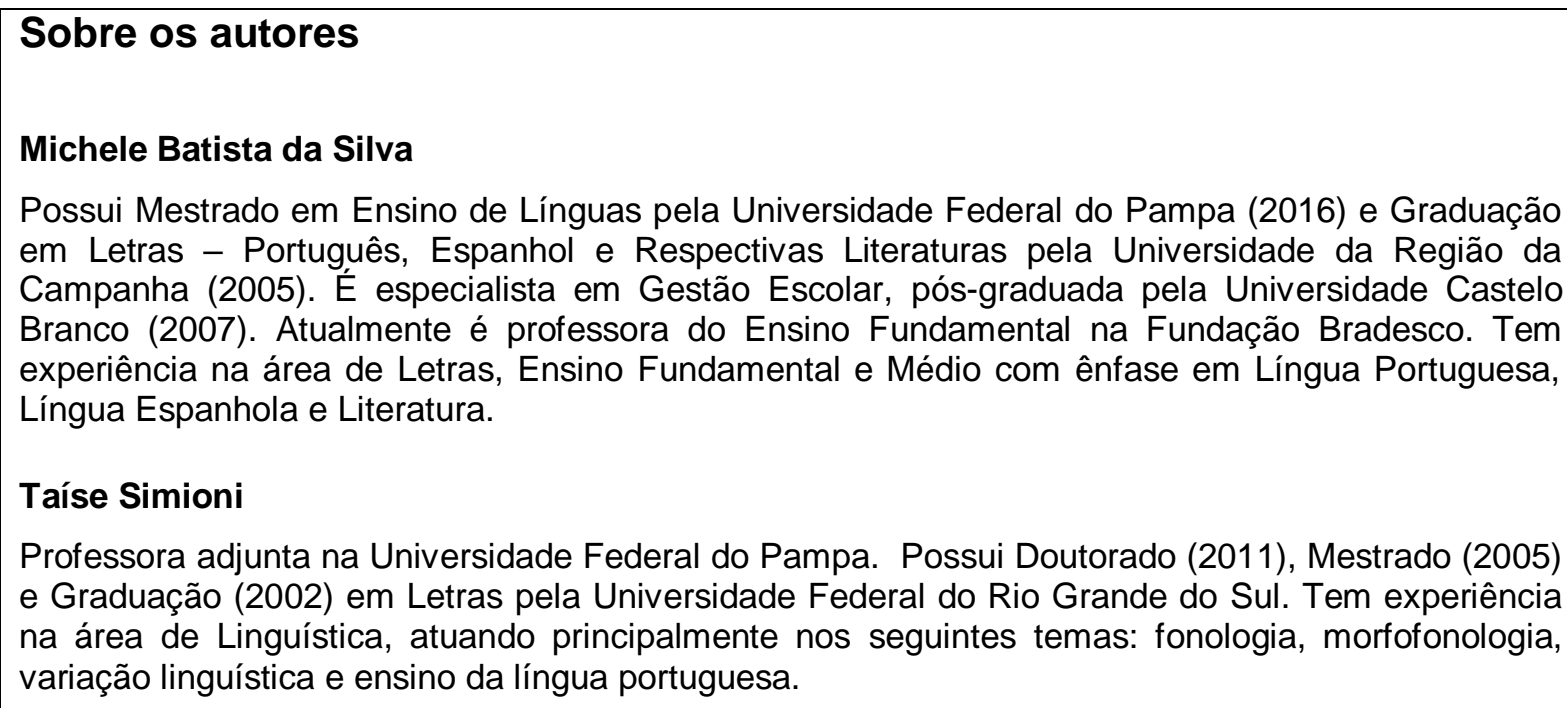
em Letras - Português, Espanhol e Respectivas Literaturas pela Universidade da Região da Campanha (2005). É especialista em Gestão Escolar, pós-graduada pela Universidade Castelo Branco (2007). Atualmente é professora do Ensino Fundamental na Fundação Bradesco. Tem experiência na área de Letras, Ensino Fundamental e Médio com ênfase em Língua Portuguesa, Língua Espanhola e Literatura.

\section{Taíse Simioni}

Professora adjunta na Universidade Federal do Pampa. Possui Doutorado (2011), Mestrado (2005) e Graduação (2002) em Letras pela Universidade Federal do Rio Grande do Sul. Tem experiência na área de Linguística, atuando principalmente nos seguintes temas: fonologia, morfofonologia, variação linguística e ensino da língua portuguesa. 